\title{
Evaluation of Drug Dose Calculation Ability of Nursing Students: An Interventional Study
}

\section{Basant Kumar Karn ${ }^{1}$, Deependra Prasad Sarraf ${ }^{2 *}$ and Erina Shrestha ${ }^{3}$}

${ }^{1}$ Department of Child Health Nursing, College of Nursing, B.P. Koirala Institute of Health Sciences, Dharan, Nepal

${ }^{2}$ Department of Clinical Pharmacology and Therapeutics, B.P. Koirala Institute of Health Sciences, Dharan, Nepal

${ }^{3}$ Department of Medical Surgical Nursing, College of Nursing, B.P. Koirala Institute of Health Sciences, Dharan, Nepal

*Corresponding Author: Deependra Prasad Sarraf, Associate Professor, Department of Clinical Pharmacology and Therapeutics, B.P. Koirala Institute of Health Sciences, Dharan, Nepal.
Received: July 31, 2020

Published: August 27, 2020

(C) All rights are reserved by Deependra

Prasad Sarraf., et al.

\begin{abstract}
The objective of the study was to evaluate the drug dose calculation ability of nursing students. A pre-post interventional study was conducted among 99 undergraduate nursing students studying in $2^{\text {nd }}$ year, $3^{\text {rd }}$ year and $4^{\text {th }}$ year. Pre-test was conducted using a self-administered 20-item questionnaire on drug dose calculation test followed by a 30 minute lecture on the methods of drug dose calculation. Post-test was conducted using the same questionnaire after a washout period of six weeks. Mean score, standard deviation, frequency and percentage were calculated. Student's t-test, one way ANOVA and McNemar Test were used for statistical analysis using SPSS version 11.5. P-value less than 0.05 was considered statistically significant. Pre-test and post-test mean score $( \pm$ Standard deviation) were $10.59 \pm 3.00$ and $15.36 \pm 2.46$ respectively. There was $45.04 \%$ increase in mean score in the post-test after the intervention and it was statistically significant (P-value $<0.05$ ). None of students scored more than $90 \%$ of mastery level in the pretest and 42 students (42.4\%) scored more than $90 \%$ of mastery level in the post-test. The mean score was highest for third year students and lowest for $2^{\text {nd }}$ year students in both pre-test and post-test; however, it was statistically not significant (P-value>0.05). Drug dose calculation ability of the students was poor in the pre-test and it significantly improved after the intervention. The study findings highlight the need for regular continuing mathematical and drug dose calculation practice among the students.
\end{abstract}

Keywords: Calculation; Drug; Dose; Nursing; Students

\section{Abbreviations}

ANOVA: Analysis of Variance; BPKIHS: B.P. Koirala Institute of Health Sciences; SD: Standard Deviation; SPSS: Statistical Package for Social Science

\section{Introduction}

Errors in drug dose calculation can be detrimental and costly to patients. Drug dose calculation and basic mathematical skills play a major role in the safe administration of medicines to the patients. Errors in drug dose calculation account for more than 15\% of medication errors [1]. Studies conducted among doctors, nurses and paramedics have reported that many healthcare providers are not sufficiently competent in drug dose calculation [2-6]. Poor understanding of the drug concentration expressed in different ways, dose calculation errors and drug administration errors are some of 
the common incompetence in nurses and other health care workers $[7,8]$.

Nurses play a vital role in different phases of a patient's medication process. Being one of the essential skills, they need adequate competency in drug dose calculation for administration of medicines safely. They need to calculate drug dose with complete accuracy and confidence [9]. However, they may face difficulties in converting ratio, mass concentration and percentage during drug dose calculation. The increased workload, time constraints, distracting environments, lack of resources and inadequate training have significant influence on the process of drug dose calculation among them [10]. The medicines are also available in various strengths like percentage and ratio which further complicate the process. Research has focused primarily on the numbers and types of errors being made by nurses. There is paucity of data on evaluation of drug doses calculation ability among nursing students. A basic knowledge of performing drug calculations would help to design training modules by educators for the nursing students that ultimately leads to safe medication administration.

\section{Aim of the Study}

The aim of the study was to evaluate the ability of drug dose calculation among nursing students studying at a tertiary hospital.

\section{Materials and Methods}

A pre-post interventional study was conducted at College of Nursing, B.P. Koirala Institute of Health Sciences (BPKIHS), Dharan, Nepal from March-May 2019. The study population was students studying Bachelor of Nursing. The students who gave consent to participate and studying in $2^{\text {nd }}$ year, $3^{\text {rd }}$ year and $4^{\text {th }}$ year were enrolled. Data were collected using a pre-tested and pre-validated semi-structured questionnaire prepared after reviewing the literature $[7,11,12]$. It consisted of two parts; the first part contained questions on sociodemographic profile (Age, academic year, schooling and Higher Secondary and mark percentage obtained in higher secondary). The second part of the questionnaire comprised of a 20-items on drug-dose calculation; the first two questions were for assessing the awareness of the students regarding drug dose calculation and rest of the questions were for evaluating their ability to calculate drug doses (Appendix 1). The questionnaire was again tested and validated in $10 \%$ of the study sample to make it more reliable and suitable to the study population and those study sample were not be used in the study. The sample size was calculated to be 99 using formula $n=z^{2 *} p^{*} q / L^{2}$ for finite population where $\mathrm{p}$ (prevalence) was $50 \%$ where $\mathrm{n}$ was sample size, $\mathrm{z}$ as level of confidence, $q$ as compliment of $p$ and $L$ as margin of error [13]. Total population enumeration sampling method was used. The purpose of the study was explained to the participants and written consent was taken. Pre-test was conducted using the self-administered semi-structured questionnaire. A one hour interactive lecture on drug dose calculation was conducted immediately after the pretest in the Lecture Theater at College of Nursing, BPKIHS. The lecture consisted of theoretical as well as practical demonstration of drug dose calculations related to various dosage forms like syrup, suspension, tablets, injections and various concentrations like percent and ratio. After washout period of six weeks, post-test was conducted using the same questionnaire used for pretesting. The survey was anonymous, calculator was permitted and 30 minutes were given to fill the questionnaire although 20 minutes time was sufficient. The students were informed to maintain anonymity in the filling of the questionnaire. The confidentiality of students was maintained. One mark was given for the correct answer and zero for the incorrect and missing answers. The total score was 18.

The data were coded and entered into Microsoft Excel 2010. The number of correct and incorrect answers was summated. Their scores were converted into percentage and also categorized into less than $90 \%$ and more than 90\%. Descriptive statistics mean, standard deviation, percentage and frequency of the variables were calculated. Student's t-test was used to determine statistically significant differences between or within groups for continuous data and one way ANOVA test and McNemar test for categorical data. All the statistical analysis was conducted using SPSS version 11.5. Pvalue less than 0.05 were considered statistically significant.

\section{Results and Discussion}

All study participants were female. Mean age of the students was $21.70 \pm 1.311$ years. Most of the students $(39,39.4 \%)$ were studying in $2^{\text {nd }}$ year (Table 1 ).

Before the intervention, only 85 (85.8\%) students agreed that it is necessary to double check our own drug dose calculations; however, after intervention 95 (95.9\%) students agreed to this statement which was statistically significant ( $P$ value $<0.05)$. The increased awareness certainly enhances the accuracy in drug dose 


\begin{tabular}{|l|c|c|c|}
\hline \multicolumn{1}{|c|}{ Variables } & Categories & Frequency & Percentage \\
\hline \multirow{3}{*}{ Academic year } & $2^{\text {nd }}$ year & 39 & 39.4 \\
\cline { 2 - 4 } & $3^{\text {rd }}$ year & 32 & 32.3 \\
\cline { 2 - 4 } & $4^{\text {th }}$ year & 28 & 28.3 \\
\hline \multirow{2}{*}{ Schooling } & Government & 10 & 10.1 \\
\cline { 2 - 4 } Higher & Boarding & 89 & 89.9 \\
\hline $\begin{array}{l}\text { Secondary } \\
\text { Government } \\
\text { college }\end{array}$ & $\begin{array}{c}\text { Private } \\
\text { college }\end{array}$ & 5 & 5.1 \\
\cline { 2 - 4 } $\begin{array}{l}\text { Marks scored } \\
\text { in Higher } \\
\text { Secondary } \\
\text { (Percentage) }\end{array}$ & $50-75$ & 54 & 94.9 \\
\cline { 2 - 4 } & $>75$ & 45 & 45.5 \\
\hline
\end{tabular}

Table 1: Socio-demographic characteristics of the students

$$
(n=99) \text {. }
$$

calculation and help to prevent dug dose related errors. It is of utmost importance to inculcate such culture at the beginning of the nursing education so that they can practice it for rest of their professional career.

Similarly before intervention, only 50 (50.5\%) students agreed that it is necessary to check the dose with a second person during drug dose calculation and after intervention 65 (65.6\%) students agreed to the statement which was statistically significant (P value $<0.05$, McNemar Test). Pre-test and post-test score of the students ranged from 4 - 16 and 8 - 18 respectively. No one scored maximum score in pre-test; however, only 18 students (18.2\%) achieved maximum score in the post-test (Figure 1).

Pre-test and post-test mean score were $10.59 \pm 3.00$ and 15.36 \pm 2.46 respectively and similar results were reported by Brown [14]. Both mean pre-test and post-test score were highest for $3^{\text {rd }}$ year students. There was $45.04 \%$ increase in mean score of the students in the post-test after the intervention which was statistically significant $(\mathrm{P}<0.05$, Paired sample t- test).

None of students scored more than $90 \%$ of mastery level in the pretest whereas 42 students (42.4\%) scored more than $90 \%$ of mastery level in the post-test (Figure 2). Similarly, majority of the nursing students failed on drug calculation test at a $90 \%$ pass level in other studies as well $[15,16]$. The students who scored less than

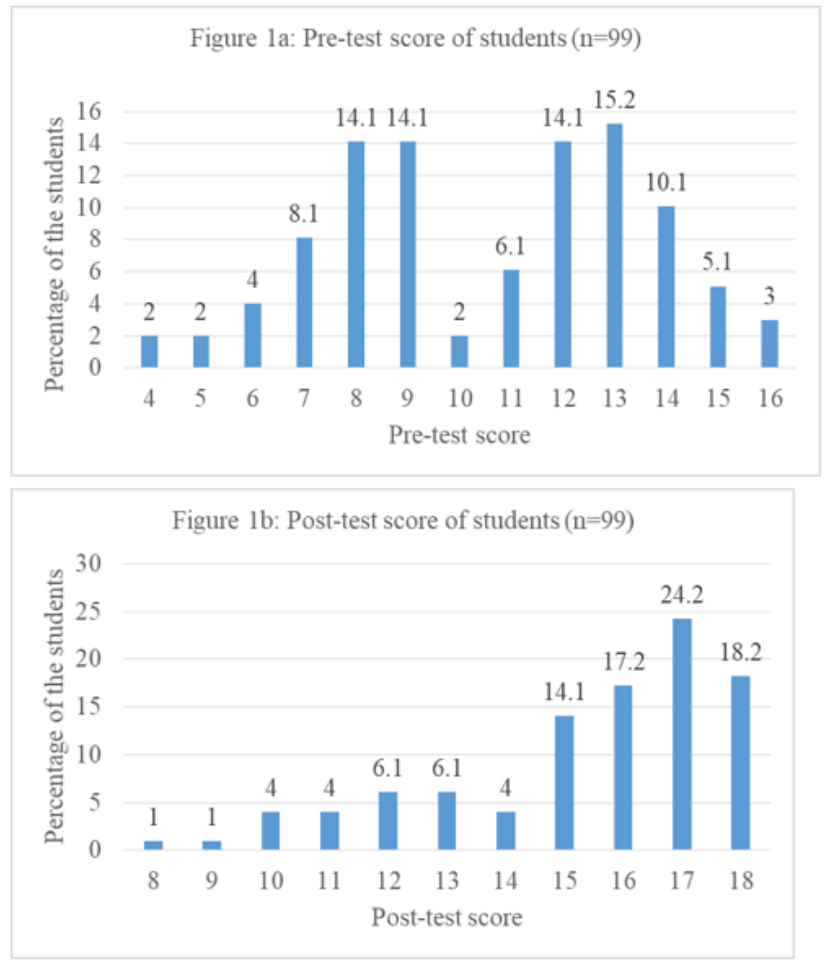

Figure 1: Pre-test and post-test score of the students $(n=99)$.

90\% may benefit from frequent education and skill test on drug dose calculation that might help to improve their skills in the area and to decrease the potential patient safety issues. Frequent and mandatory drug calculation modules, both practical and theoretical, should be included in the nursing curriculum from $1^{\text {st }}$ to $4^{\text {th }}$ year which will reinforce the knowledge and skill and make them more competent.

Errors in drug dose calculation occur either because of the numerical inability of the students to perform basic functions such as addition, subtraction, multiplication, division and use of decimals and fractions or due to their inability to conceptually extract the correct information from the drug dose calculation problems in order to set up the mathematical calculations needed [17]. The students who perform poorly on the written tests on drug dose calculations are assumed to have poor skills in practice. Therefore, the nurse educationist should also focus on the education of nursing 
students regarding accurate drug dose calculations.

As age increased, mean score increased both in pretest and post-test; however, it was statistically not significant ( $P$ value $>0.05$ ). Third year students' score was highest in both pre-test and post-test compared to $2^{\text {nd }}$ year and $4^{\text {th }}$ year students' score; however, it was statistically not significant ( $\mathrm{P}$ value $>0.05$ ). Those students who have completed their schooling from government school scored higher both in pre- and post-test than those who had completed their schooling from boarding school; however, it was statistically not significant (P value $>0.05)$. The students having 50 - 75\% mark in their higher secondary had got less mean score in the pretest than those with more than $75 \%$ mark. After the intervention the mean score of both these group of students increased in the post-test; however, it was statistically not significant (P value $>0.05$ ) (Table 2). Similar findings were also reported by Grandell-Niemi., et al [15]. Therefore, previous knowledge and experience on mathematical skills should be considered before planning and implementing effective modules on drug dose calculation ability among nursing students.

\begin{tabular}{|c|c|c|c|c|}
\hline Variables & Categories & $\begin{array}{c}\text { Pre-test } \\
\text { mean score } \\
( \pm \text { SD) }\end{array}$ & $\begin{array}{c}\text { Post-test } \\
\text { mean score } \\
( \pm \mathrm{SD})\end{array}$ & P-value \\
\hline \multirow{3}{*}{$\begin{array}{l}\text { Academic } \\
\text { year }\end{array}$} & $2^{\text {nd }}$ year & $10.10 \pm 2.78$ & $14.92 \pm 2.67$ & \multirow{3}{*}{$0.421 *$} \\
\hline & $3^{\text {rd }}$ year & $11.22 \pm 2.84$ & $16.03 \pm 1.55$ & \\
\hline & $4^{\text {th }}$ Year & $10.54 \pm 3.42$ & $15.21 \pm 2.87$ & \\
\hline \multirow{2}{*}{ Schooling } & Government & $11.00 \pm 3.43$ & $16.10 \pm 1.72$ & \multirow{2}{*}{$0.936^{\$}$} \\
\hline & Boarding & $10.54 \pm 2.97$ & $15.28 \pm 2.52$ & \\
\hline \multirow{2}{*}{$\begin{array}{l}\text { Higher } \\
\text { Secondary }\end{array}$} & $\begin{array}{c}\text { Government } \\
\text { college }\end{array}$ & $10.00 \pm 2.91$ & $16.60 \pm 1.14$ & \multirow{2}{*}{$0.420^{\$}$} \\
\hline & $\begin{array}{l}\text { Private } \\
\text { college }\end{array}$ & $10.62 \pm 3.02$ & $15.30 \pm 2.49$ & \\
\hline \multirow{2}{*}{\begin{tabular}{|l|} 
Mark in \\
Higher \\
Secondary \\
(Percentage)
\end{tabular}} & Up to 75 & $9.59 \pm 2.91$ & $14.54 \pm 2.28$ & \multirow[b]{2}{*}{$0.049^{\$}$} \\
\hline & $>75$ & $12.00 \pm 2.62$ & $16.53 \pm 2.03$ & \\
\hline
\end{tabular}

Table 2: Correlation between baseline variables and mean score obtained by the students $(\mathrm{n}=99)$.

*One way ANOVA test; \$Student's t-test.

The educationist should address mathematical skills and concepts, linking numeracy competency with meaning and context and teaching drug calculation formulae and practical calculation examples should be provided for developing the competency in drug dose calculations [18]. We have to revise effective teaching and learning strategies to support and facilitate nursing students to learn this skill and make them competent. Perhaps there is a need for collaboration between the Nursing Council of Nepal and other relevant authority to establish a core set of competencies and good nursing practice for clinical education of nursing health care professionals. It would be more practical to include drug dose calculation related objective problems during service entry examination of nurses. Researches need to be conducted frequently to check the competencies in drug dose calculation of the nursing students as well as nursing personals. With the advent of more accessible and affordable computer and mobile technology, more use of online materials should be encouraged to enhance mathematical skills among nurses. Our study had some limitations also. The sample size of the study was small. The arithmetical, conceptual and computational errors were not evaluated. Being a single-center study, the findings may not be generalized to other nursing students studying at different institutions.

\section{Conclusion}

Our study showed that the drug dose calculation ability of nursing students was poor in the pre-test which significantly improved after the intervention. The study findings highlight the need for regular continuing drug dose calculation practice and the use of other educational measures to ensure a higher competency in drug dose calculation among the students. Our study recommends frequent reinforcement of drug dose calculation both in the classroom and ward posting through practice and assessment.

\section{Acknowledgments}

We would like to thank the nursing students who participated in the study and Mr. Dharanidhar Baral for the help in the statistical analysis.

\section{Conflict of Interest}

None.

Appendix 1: The questionnaire

1. When calculating drug doses, is it necessary to double-check your own calculations?

a. Yes* b. No c. Do not know

2. When calculating drug doses, it necessary to check the dose with a second person? 
a. Yes* b. No c. Do not know

3. Convert $5 \mathrm{mg}$ into microgram.

a. $2000 \mathrm{mg}$ b. $3000 \mathrm{mg} \mathrm{c.} 4000 \mathrm{mg} \mathrm{d} .5000 \mathrm{mg}^{*}$

4. $8 \mathrm{~mL}$ of a drug solution contains:

a. 8 microlitre b. 80 microlitre c. 800 microlitre d. $8000 \mathrm{mi}-$ crolitre*

5. How much sodium (in grams) is there in a $500 \mathrm{~mL}$ infusion of sodium chloride $0.9 \%$ ?

a. $9 \mathrm{~g} \mathrm{b.4.5g*}$ c. $2.5 \mathrm{~g}$ d. $1.5 \mathrm{~g}$

6. You have a $5 \mathrm{~mL}$ ampoule of dopexamine $1 \%$. How many milligrams of dopexamine are there in the ampoule?

a. $20 \mathrm{mg} \mathrm{b.} 30 \mathrm{mg} \mathrm{c.} 40 \mathrm{mg} \mathrm{d} .50 \mathrm{mg}^{*}$

7. You have a $10 \mathrm{~mL}$ ampoule of adrenaline 1 in 1000 . How much adrenaline in milligrams does the ampoule contain?

a. $10 \mathrm{mg}^{*}$ b. $20 \mathrm{mg} \mathrm{c.} 30 \mathrm{mg} \mathrm{d} .40 \mathrm{mg}$

8. You plan to suture an $80 \mathrm{~kg}$ patient. Given the maximum safe dose of lignocaine is $3 \mathrm{mg} / \mathrm{kg}$, what is the maximum safe volume, in $\mathrm{mL}$, of $2 \%$ lignocaine solution that can be given?

a. $8 \mathrm{ml}$ b. $10 \mathrm{ml} \mathrm{c.} 12 \mathrm{ml}^{*}$ d. $14 \mathrm{ml}$

9. Sodium hypochlorite is available as $10 \%$ solution in 1 litre bottle. How much water should be added to this solution so that its concentration becomes $2 \%$ ?

a. $1000 \mathrm{ml}$ b. $2000 \mathrm{ml} \mathrm{c.} 3000 \mathrm{ml} \mathrm{d.} 4000 \mathrm{ml}^{*}$

10. You are attending the cardiac arrest of a 60 -year-old male. How many $\mathrm{mL}$ of 1:10000 adrenaline do you need to give a dose of $1 \mathrm{mg}$ of adrenaline?

a. $0.5 \mathrm{ml}$ b. $1 \mathrm{ml} \mathrm{c.} 10 \mathrm{ml}^{*}$ d. $20 \mathrm{ml}$

11. Atropine vials are found on emergency trolleys in our hospital. Each $10 \mathrm{~mL}$ vial contains $1 \mathrm{mg}$ of atropine. What is the concentration in $\mathrm{mg} / \mathrm{mL}$ of this solution?

a. $\quad 0.01 \mathrm{mg} / \mathrm{ml} \mathrm{b.} 0.1 \mathrm{mg} / \mathrm{ml}^{*}$ c. $1 \mathrm{mg} / \mathrm{ml} \mathrm{d} .10 \mathrm{mg} / \mathrm{ml}$

12. A $45 \mathrm{~kg}$ female patient develops symptomatic bradycardia. You elect to treat this with atropine, 20 microgram $/ \mathrm{Kg}$, given intravenously. How many $\mathrm{mL}$ of an atropine (available as 1 $\mathrm{mg}$ in $10 \mathrm{~mL}$ ) will be required?

a. $3 \mathrm{~mL}$ b. $6 \mathrm{~mL} \mathrm{c.} 9 \mathrm{~mL}^{*}$ d. $12 \mathrm{~mL}$

13. The physician orders $375 \mathrm{mg}$ of cefuroxime for the patient. The drug is available in $750 \mathrm{mg}$ vial. You plan to dilute it in
$10 \mathrm{~mL}$ of sterile water. How much should you give to your patient?

a. $5 \mathrm{~mL}^{*}$ b. $6 \mathrm{~mL} \mathrm{c.} 7 \mathrm{~mL} \mathrm{~d} .8 \mathrm{~mL}$

14. A pediatric patient recovering from accidental fall is about to be given with $130 \mathrm{mg}$ paracetamol syrup. The drug is available in $250 \mathrm{mg}$ per $5 \mathrm{~mL}$ preparation. How much should you give to your patient?

a. $\quad 1.6 \mathrm{~mL}$ b. $2.6 \mathrm{~mL}^{*}$ c. $3.6 \mathrm{~mL}$ d. $4.6 \mathrm{~mL}$

15. You need to give a patient 125 micrograms of digoxin orally. You have digoxin elixir 50 micrograms/mL supplied with a dropper pipette. How much do you need to draw up for this patient?

a. $1 \mathrm{~mL}$ b. $1.5 \mathrm{~mL}$ c. $2 \mathrm{~mL}$ d. $2.5 \mathrm{~mL}^{*}$

16. You need to give $1 \mathrm{~g}$ of erythromycin orally. You have erythromycin suspension $250 \mathrm{mg}$ in $5 \mathrm{~mL}$. How much of the suspension do you need to give?

a. $20 \mathrm{~mL}^{*}$ b. $30 \mathrm{~mL}$ c. $40 \mathrm{~mL}$ d. $50 \mathrm{~mL}$

17. You have gentamicin injection $40 \mathrm{mg} / \mathrm{mL}$ in $2 \mathrm{~mL}$ ampoules. Amount of gentamicin required is $4 \mathrm{mg} / \mathrm{kg}$ for a $60 \mathrm{~kg}$ patient. How many ampoules will you need?

a. 6 ampoules* b. 8 ampoules c. 10 ampoules d. 12 ampoules

18. The physician orders $1,500 \mathrm{mg}$ of calcium carbonate for the patient. The drug is available in $250 \mathrm{mg}$ tablets. How many tablets should be given to the patient?

a. 2 tablets b. 4 tablets c. 6 tablets* d. 8 tablets

19. A patient is prescribed $75 \mathrm{mcg}$ of levothyroxine sodium (thyroxine sodium) but the strength of the tablets available is 25 mcg. How many tablets are required?

a. 1 tablet b. 2 tablets c. 3 tablets* d. 4 tablets

20. Determine the number of tablets to administer $0.25 \mathrm{mg}$ of the drug from a medication stock of 62.5 microgram per tablet.

a. 1 tablet b. 2 tablets c. 3 tablets d. 4 tablets*

*The correct answer.

\section{Bibliography}

1. Lesar TS., et al. "Factors related to errors in medication prescribing". The Journal of the American Medical Association 2077.4 (19977): 312-317. 
2. Conroy S., et al. "Educational interventions to reduce prescribing errors". Archives of Disease in Childhood 93.4 (2008): 313-315.

3. Eastwood KJ. “Can paramedics accurately perform drug calculations?" Emergency Medicine Journal 26.2 (2009): 117-118.

4. Wheeler DW., et al. "Calculation of doses of drugs in solution: are medical students confused by different means of expressing drug concentrations?" Drug Safety 27.10 (2004): 729-734.

5. Bindler R., et al. "Medication calculation ability of registered nurses". Image The Journal of School Nursing 23.4 (1991): 221-224.

6. Wheeler DW., et al. "Doctors' confusion over ratios and percentages in drug solutions: the case for standard labeling". Journal of the Royal Society of Medicine 97.8 (2004): 380-353.

7. Rolfe S., et al. "Ability of hospital doctors to calculate doses". British Medical Journal 310.6988 (1995):1173-1174.

8. Jennings BM., et al. "The nurse's medication day". Qualitative Health Research 21.10 (2011): 1441-1451.

9. Toney-Butler TJ., et al. "Dose Calculation (Ratio and Proportion)". StatPearls Publishing (2020).

10. Simpson CM., et al. "A survey of drug-dose calculation skills of Australian tertiary hospital doctors". Medical Journal of Australia 190.3 (2009): 117-120.

11. Glover ML., et al. 'Assessing pediatrics residents' mathematical skills for prescribing medication: a need for improved training". Academic Medicine 77.10 (2002): 1007-1010.

12. Oshikoya KA., et al. "Ability of medical students to calculate drug doses in children after their paediatric attachment". Pharmacy Practice (Granada) 6.4 (2008): 191-196.

13. Brown DL. "Does $1+1$ still equal 2? A study of the mathematic competencies of associate degree nursing students". Nurse Educator 27.3 (2002): 132-135.

14. Hubble MW., et al. "Medication calculation skills of practicing paramedics". Prehospital Emergency Care 4.3 (2000): 253260.
15. Grandell-Niemi H., et al. "Medication calculation skills of nurses in Finland". Journal of Clinical Nursing 12.4 (2003): 519-528.

16. Wright K. "An exploration into the most effective way to teach drug calculation tests to nursing students". Nurse Education Today 25.6 (2005): 430-436.

17. Jukes L., et al. "Concerns about numeracy skills of nursing students". Nurse Education in Practice 6.4 (2006): 192-198.

18. Wright K. "The assessment and development of drug calculation skills to nurse education-a clinical debate". Nurse Education Today 29.5 (2009): 544-548.

\section{Assets from publication with us}

- Prompt Acknowledgement after receiving the article

- Thorough Double blinded peer review

- Rapid Publication

- Issue of Publication Certificate

- High visibility of your Published work

Website: www.actascientific.com/

Submit Article: www.actascientific.com/submission.php

Email us: editor@actascientific.com

Contact us: +919182824667 